\title{
DILEMAS E DESAFIOS DO ENSINO DA GRADUAÇÃO EM ENFERMAGEM DURANTE A PANDEMIA DA COVID-19
}

CAPITULO

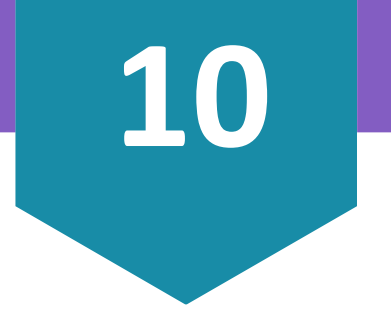

Carolina Caruccio Montanari

Enfermeira, Doutora em Medicina pela Universidade Federal do Rio Grande do Sul - UFRS Prof. Adjunta do Curso de Enfermagem da Faculdade de Ciências da Saúde Moinhos de Vento

\section{Louisiana Carolina Ferreira de Meireles}

Fisioterapeuta. Doutora em Ciências Biológicas pela Universidade Federal do Rio Grande do Sul - UFRS Prof. Adjunta do Curso de Enfermagem da Faculdade de Ciências da Saúde Moinhos de Vento Márcia Otero Sanches Enfermeira. Doutora em Enfermagem pela Universidade Federal do Rio Grande do Sul - UFRS Coord.e Prof. Adjunta do Curso de Enfermagem da Faculdade de Ciências da Saúde Moinhos de Vento

Maria José Santos de Oliveira

Enfermeira. Doutoranda do Programa de Pós-Graduação em Neurociências da Universidade Federal do Rio Grande do Sul - UFRS. Prof. Adjunta do Curso de Enfermagem da Faculdade de Ciências da Saúde Moinhos de Vento

Martina Madalena Pedroso

Fisioterapeuta. Mestra em Ciências da Saúde: Cardiologia e Ciências Cardiovasculares da Universidade Federal do Rio Grande do Sul - UFRS. Prof. Adjunta do Curso de Enfermagem da Faculdade de Ciências da Saúde Moinhos de Vento

\section{RESUMO}

O objetivo deste trabalho é descrever as atividades não presenciais no ensino da graduação em enfermagem, no contexto da pandemia da COVID-19, em uma instituição de ensino superior (IES) no sul do Brasil. Método: trata-se de um relato de experiência com a descrição das atividades de ensino remoto realizadas no curso de graduação em enfermagem de uma IES privada da região de Porto Alegre, Rio Grande do Sul, no período de março de 2020 a setembro de 2021. Resultados: os professores procuraram diversificar suas metodologias de ensino, não ministrando apenas aulas expositivas e dialogadas, mas procurando estimular diferentes formas de aprendizagem visual, auditiva, cinestésica e leitura/escrita e, dessa forma, manter um bom nível de compreensão e assimilação de conteúdos para todos os alunos. Conclusão: a pandemia veio para mostrar que o uso da tecnologia no ensino será uma realidade daqui para frente. E por este motivo o sistema de ensino deve estar preparado para se desenvolver e buscar alternativas para sanar as dificuldades percebidas no ensino-aprendizado dos educandos.

Palavras-chave: Educação em enfermagem, pandemia covid-19, aprendizado on-line, educação superior 


\section{INTRODUÇÃO}

A educação para a formação de novos recursos humanos para a área da saúde é complexa. Pois, além de instrumentalizar o acadêmico para o conhecimento técnico científico contribui para sua transformação biopsicossocial. A educação é parte de um processo histórico e cultural que vem sofrendo atualizações ao longo dos tempos ${ }^{1}$. Predominantemente desde o início das escolas de enfermagem no Brasil e no mundo, o ensino na enfermagem ocorreu sempre de forma presencial, enfatizando o desenvolvimento de habilidades e competências técnicas e operacionais da profissão. Além destas habilidades é preciso no decorrer da formação do bacharel em enfermagem desenvolver o do acadêmico para a liderança de equipe, coordenação, ensino, pesquisa e cuidado. Mediante a situação epidemiológica ocasionada pela pandemia covid-19, assim declarada pela Organização Mundial de Saúde em março de 2020 no Brasil e no mundo, todas as atividades que envolvessem circulação de pessoas sofreram paralisação e o isolamento social foi recomendado. Esta paralisação alterou profundamente os calendários escolares e as atividades educacionais em todos os níveis, etapas, anos/séries e modalidades de educação e ensino no país.

Tão logo os estados brasileiros publicaram seus decretos, como medida emergencial para suprir as demandas assistenciais de formação de novos profissionais da área da saúde, o Ministério da Educação, por meio da portaria $\mathrm{n}^{\circ} 343$, de 17 de março de 2020, possibilitou a substituição das aulas presenciais por aulas que utilizassem os meios de plataformas digitais, fazendo com que as Instituições de Ensino Superior (IES) assumissem o formato remoto, inclusive para o ensino na Enfermagem ${ }^{3}$. A mesma portaria ainda se mantém em vigor no país até o presente momento, visto que passamos pelo recrudenciamento da pandemia no primeiro semestre do ano letivo de 2021. Deste modo, grande parte das redes e instituições de ensino permaneceram com as escolas fechadas, tendo somente atividades remotas. Diante deste fato, observa-se que a situação da educação em todos os níveis no país é extremamente delicada. Há um significativo aumento das desigualdades de acesso à internet e a equipamentos para assistir às aulas ocasionando aumento da evasão escolar, principalmente no ensino público. Além disso, ocorre também aumento do estresse socioemocional dos estudantes e suas respectivas famílias preocupados com 0 seu desenvolvimento futuro dos educandos ${ }^{4}$.

O ensino remoto, também denominado on-line, faz uso de tecnologias digitais para o ensino e foi a estratégia adotada que permitiu a continuidade do processo educacional, sem a necessidade da presença física durante o período da pandemia. É importante ressaltar que ensino remoto é diferente de educação a distância (EaD). A modalidade $\mathrm{EaD}$ é regulamentada pelo parecer CNE/CES no: 564/2015 que trata das Diretrizes e Normas Nacionais para a oferta de Programas e Cursos de Educação Superior na Modalidade a Distância e define a especificidade e as características desta 
modalidade educativa. Para implementação da modalidade nas instituições de ensino é necessário que haja a contextualização e articulação efetivamente de um "ambiente virtual multimídia interativo", com convergência digital, como "espaço" de relações humanas e a partir de uma visão de educação, com qualidade social, para todos, a partir da garantia de padrão de qualidade e reais condições de infraestrutura, laboratórios, base tecnológica, com pessoal qualificado, políticas de acesso, acompanhamento e avaliação compatíveis ${ }^{5}$. Isso significa que para um curso ser ofertado a distância, ele precisa ter um desenho pedagógico, que busque atender os objetivos de aprendizagem daquela formação e as Instituições de Ensino Superior não teriam condições em curto espaço de tempo e investimento financeiro para adequar infraestrutura e formação docente. Além disso, temse uma grande discussão pedagógica entre os conselhos que regimentam as profissões e instituições de ensino em relação a formação de profissionais de saúde exclusivamente pelo EAD e a necessidade destes acadêmicos de vivenciar a simulação prática de forma presencial.

No entanto, neste momento emergencial o ponto comum entre o ensino remoto e o EaD é a utilização das tecnologias digitais ${ }^{6}$. Além dessas modalidades é importante esclarecer o conceito de ensino híbrido. O hibridismo é inerente ao processo educacional ${ }^{7}$, pois contempla a "mistura" de espaços, atividades e metodologias síncronas, que tende a se expandir cada vez mais devido ao avanço das tecnologias digitais ${ }^{8}$.

Neste sentido, a formação superior de profissionais para a saúde foi rapidamente adaptada do ensino presencial para o remoto. Infelizmente, algumas habilidades e competências profissionais, especialmente dos anos iniciais da formação, como por exemplo, fundamentos básicos da enfermagem ficou com seu desenvolvimento pratico prejudicado, pois a mesma exige a presencialidade e proximidade entre profissionais e pacientes nos campos práticos e de laboratórios não era possível. Esta indisponibilidade é indiscutível devido a necessidade do protocolo de distanciamento social e ao risco de contágio. Além disso, naqueles momentos de maior disseminação do coronavírus todos os centros de saúde, hospitais, clínicas etc., estavam superlotados prestando o atendimento aos pacientes infectados com a covid-199. Deste modo, devido ao risco de exposição e contaminação dos acadêmicos e seguindo os protocolos do ministério da educação e da secretária de saúde do estado do Rio Grande do Sul, não foi possível realizar as atividades práticas presenciais. Contudo, seguimos realizando as atividades de laboratório remoto, exemplificando, contextualizando e fomentando a discussão dos acadêmicos para as atividades propostas.

Entendemos que a enfermagem corresponde a uma grande força de trabalho na área da saúde e o atraso na formação de novos profissionais, pode impactar diretamente na saúde local e/ou regional de uma forma geral 10. Pois, com a falta de novos profissionais, a contaminação dos que estão na linha de frente, haverá mais sobrecarga de trabalho e risco de eventos adversos aos pacientes. Mas não basta apenas formar novos profissionais, 
se faz necessário tornar o educando protagonista de seu aprendizado, para que as dificuldades no processo de ensino e aprendizagem sejam discutidas e resolvidas ao longo da formação. Assim, reduzindo os déficits na sua formação profissional, pois um acadêmico da área da saúde com dificuldades em desenvolver suas habilidades e competências, poderá sofrer reflexos na vida profissional podendo impactar diretamente na segurança do paciente.

Neste sentido, diversas Instituições de Ensino Superior (IES) em todo o mundo precisaram modificar o formato de suas aulas, visando minimizar o impacto da pandemia na formação destes profissionais. Os problemas encontrados e as soluções implementadas foram semelhantes, sendo necessário resiliência e eficiência para implementação de educação on-line eficaz nas ciências da saúde. Estratégias foram incorporadas para garantir o aprendizado bem-sucedido, como a discussão de cenários clínicos simulados e a utilização de softwares que simulassem habilidades clínicas ${ }^{9}$. Com todas estas modificações, houve uma grande aceleração do uso da tecnologia de informação e comunicação que possibilitaram a continuidade dos estudos a milhares de estudantes pelo mundo todo. Diante deste cenário, este estudo teve como objetivo descrever as atividades não presenciais no ensino da graduação em enfermagem, no contexto da pandemia da COVID19, em uma instituição de ensino superior (IES) no sul do Brasil.

\section{METODOLOGIA DE ESTUDO}

O Presente trabalho é um relato de experiência desenvolvido a partir da descrição das atividades de ensino síncronas e assíncronas realizadas no curso de graduação em enfermagem de uma IES privada da região de Porto Alegre, Rio Grande do Sul, no período de março de 2020 a setembro de 2021.

A referida IES oferece o curso de graduação em Enfermagem e quatorze cursos de pós-graduação lato sensu em diversas áreas, sendo elas: Enfermagem, Farmácia, Fisioterapia, Gestão em Saúde, Medicina, Nutrição e Psicologia. Todos os cursos da instituição passaram pela virtualização em decorrência da pandemia. A instituição é mantida por um hospital de grande porte e complexidade, tornando o acesso a práticas de formação profissional em saúde em nível terciário, mais ágeis e acessíveis.

Por se tratar de um relato de experiência, este estudo não foi avaliado por um comitê de ética. Contudo, vale ressaltar que a divulgação de fotos que envolveram estudantes foi autorizada.

\section{RESULTADOS}

Desde o início de março de 2020, as aulas da graduação em enfermagem passaram a acontecer por meio da utilização de plataforma digital, de forma síncrona. A escolha pela modalidade síncrona aconteceu porque originalmente trata-se de um curso presencial, que diante do cenário precisou passar para o ensino remoto, não sendo caracterizado por um curso EaD. Além disso, as aulas síncronas, realizadas ao vivo e sem gravação, 
facilitam a comunicação entre educador e educando, pois permitem que o professor perceba as dificuldades e possa saná-las em tempo real, facilitam que os estudantes possam esclarecer suas dúvidas ao longo da aula e, além disso, proporcionam a utilização de metodologias ativas de aprendizagem. Embora o formato das aulas tenha se modificado, os professores mantiveram e respeitaram os planos de ensino e carga horária das disciplinas. Dessa forma, os estudantes não foram prejudicados com relação ao conteúdo abordado.

Mesmo diante do ensino remoto, os docentes foram instigados a exercerem o protagonismo no processo de ensino e aprendizagem, mas acima disso a estimular os educandos que também fossem protagonistas de seu aprendizado. Neste sentido, vale ressaltar que o professor deve estar ciente que é facilitador do conhecimento, mas não o ator principal no cenário. Um aprendizado efetivo depende do envolvimento do aluno como ator principal. O sujeito ativo deve ser o aluno, que planeja, busca e constrói seu próprio conhecimento, amparado pelo facilitador deste processo, o educador.

Os professores procuraram variar suas metodologias de ensino, não ministrando apenas aulas expositivas e dialogadas, mas procurando estimular as diferentes formas de aprendizagem visual, auditiva, cinestésica e leitura/escrita e, dessa forma, manter um bom nível de compreensão e assimilação de conteúdos para todos os alunos. Além de explorar os diferentes níveis cognitivos propostos pela Taxonomia de Bloom ${ }^{11}$, utilizando níveis de complexidade crescente - do mais simples ao mais complexo.

Dentre as metodologias ativas utilizadas, podemos destacar: discussão de casos clínicos e exames, utilização de laboratórios virtuais de anatomia e histologia, construção de maquetes e mapas mentais, exibição e produção de recursos audiovisuais, discussão de artigos científicos e diretrizes, elaboração de resumos científicos e demonstração e realização supervisionada (on-line) de técnicas e procedimentos de enfermagem.

A discussão de casos clínicos e exames tem o objetivo de desenvolver o raciocínio clínico, os estudantes de enfermagem receberam casos clínicos fictícios e reais, contendo informações sobre um paciente, como idade, gênero, fatores de risco, doenças pregressas, doença atual, sinais e sintomas, sinais vitais, exames laboratoriais e de imagem. A partir disso, são instigados a pensar o que está acontecendo com o paciente, elaborar os diagnósticos de enfermagem e definir as condutas do enfermeiro.

Utilização de laboratórios virtuais de anatomia e histologia, principalmente para as disciplinas iniciais da graduação, que envolvem o conhecimento de anatomia e histologia, foram utilizados os laboratórios virtuais, através de sites gratuitos. Para anatomia, foram utilizados sites que permitem não somente a visualização de estruturas anatômicas nas vistas anterior, posterior e laterais, mas também a dissecação (figura 1). Para a histologia, os estudantes puderam observar as células e tecidos como se estivesse visualizando estas estruturas no microscópio (figura 2). 

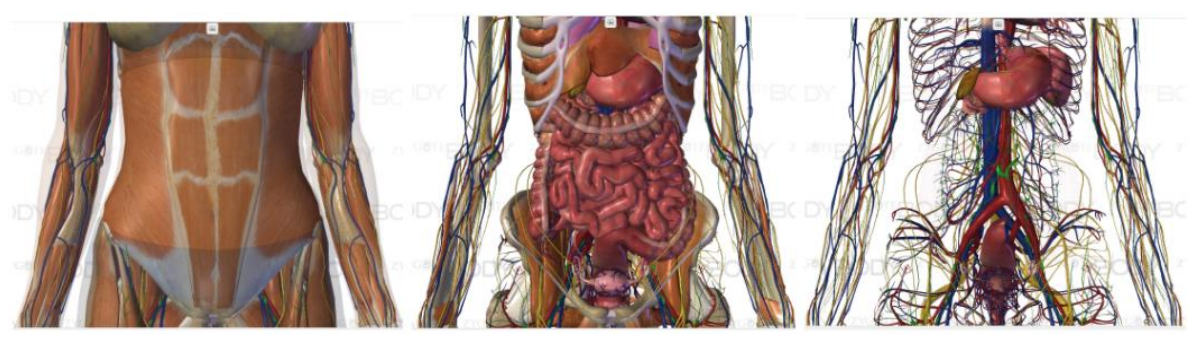

Figura 1. Região abdominal em vista superficial, intermediária e profunda. Disponível: https://www.zygotebody.com/\#nav=1.62,100.1,56.76,0,0,0,0\&sel=p:;h:;s:;c:0;o:0\&layers=0,1,4072

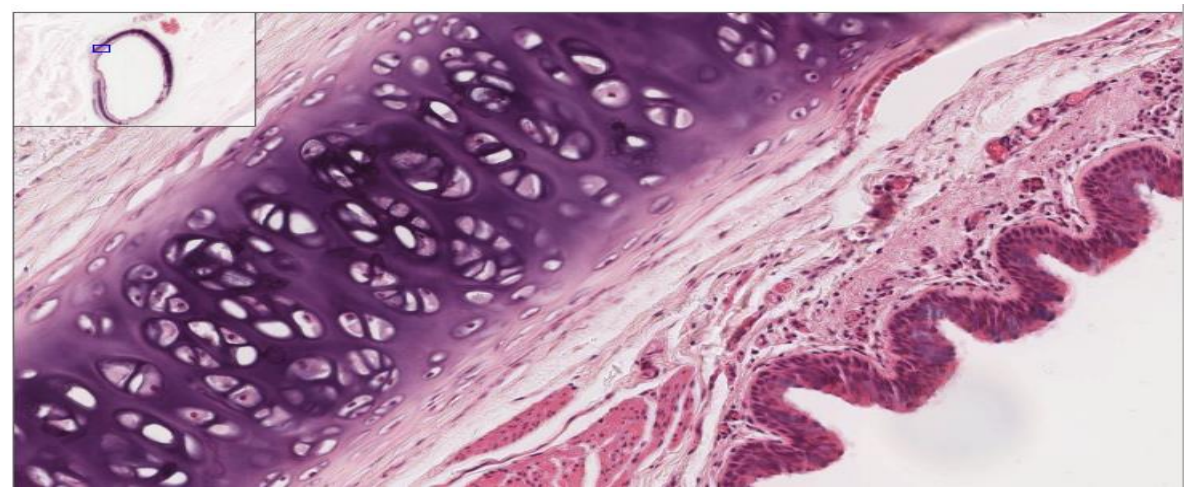

Figura 2. Corte transversal da traqueia. Disponível: http://zoomify.lumc.edu/respiratory/respiratory_main.htm

A construção de maquetes, nesta atividade os alunos são estimulados a construir maquetes de células, tecidos e órgãos corporais, visando facilitar o entendimento tridimensional dessas estruturas e a partir disso compreender a fisiologia. Um exemplo disso, foi a construção de uma maquete do néfron (figura 3), proposta na disciplina de Sistema Renal. 


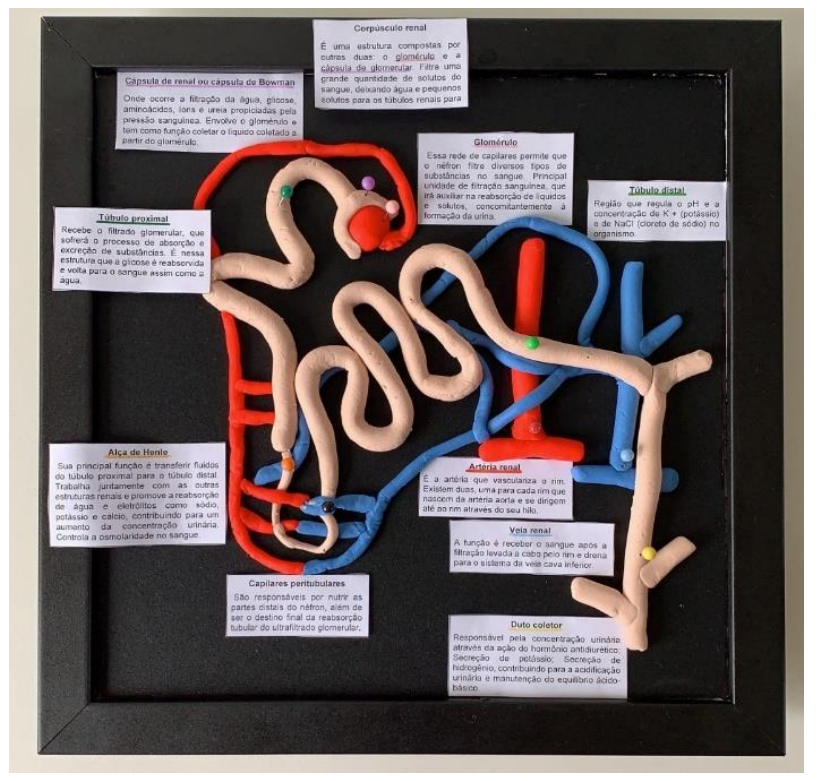

Figura 3. Representação do néfron em maquete. Fonte: Valotta NC, Caye BL, 2021.

A elaboração de mapas mentais que são utilizados visando a organização visual das informações e a memorização de processos corporais, bem como atribuições do enfermeiro. Na disciplina de Sistema Respiratório, cada aluno construiu seu mapa mental sobre hematose (figura 4).

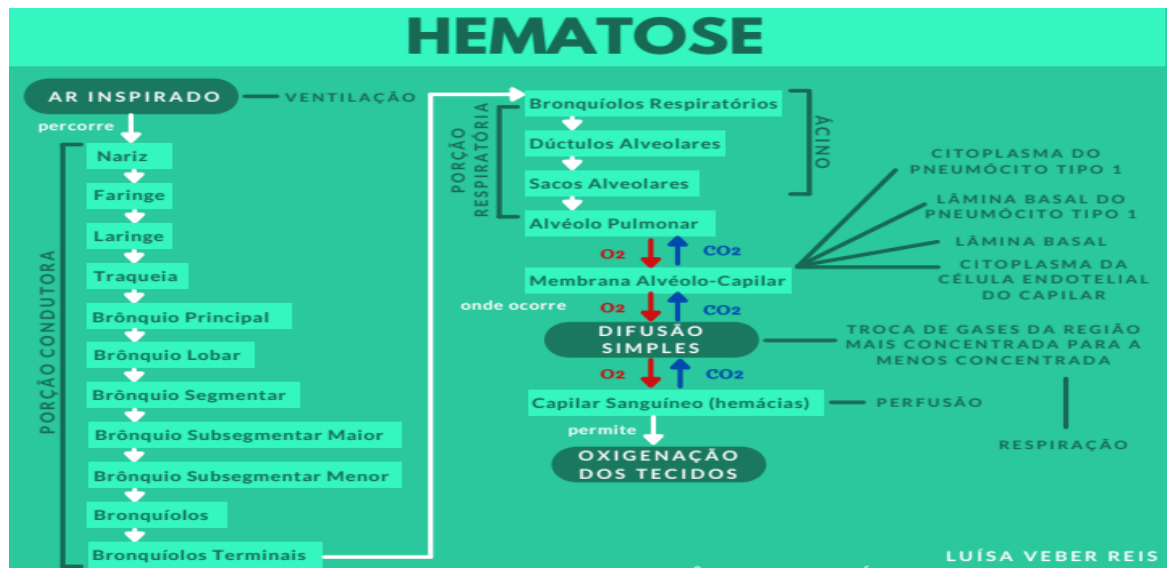

Figura 4. Mapa mental de hematose. Fonte: Reis LV, 2021. 
A exibição e produção de recursos audiovisuais: sabe-se que assistir e elaborar produções audiovisuais engrandece 0 aprendizado. Estas produções podem ser usadas para reflexão sobre os próprios valores e em relação a questões profissionais e sociais. Um exemplo disso, foi a atividade realizada na disciplina de Assistência de Enfermagem em Saúde Mental, na qual a professora exibiu o filme "Nise: O Coração da Loucura" e após, com base no filme, instigou os alunos a refletir sobre o cuidado dos pacientes psiquiátricos.

Principalmente a produção audiovisual, instiga o potencial criativo e inovador dos estudantes. Na disciplina de Assistência de Enfermagem Materno-Infantil, os alunos foram estimulados a elaborar uma campanha, no mês de agosto, de conscientização pelo fim da violência contra a mulher. Algumas estudantes utilizaram maquiagens, simulando situações de violência e chamando a atenção para a prevenção (figura 5). As imagens foram veiculadas nas redes sociais dos alunos que optaram por fazê-lo.

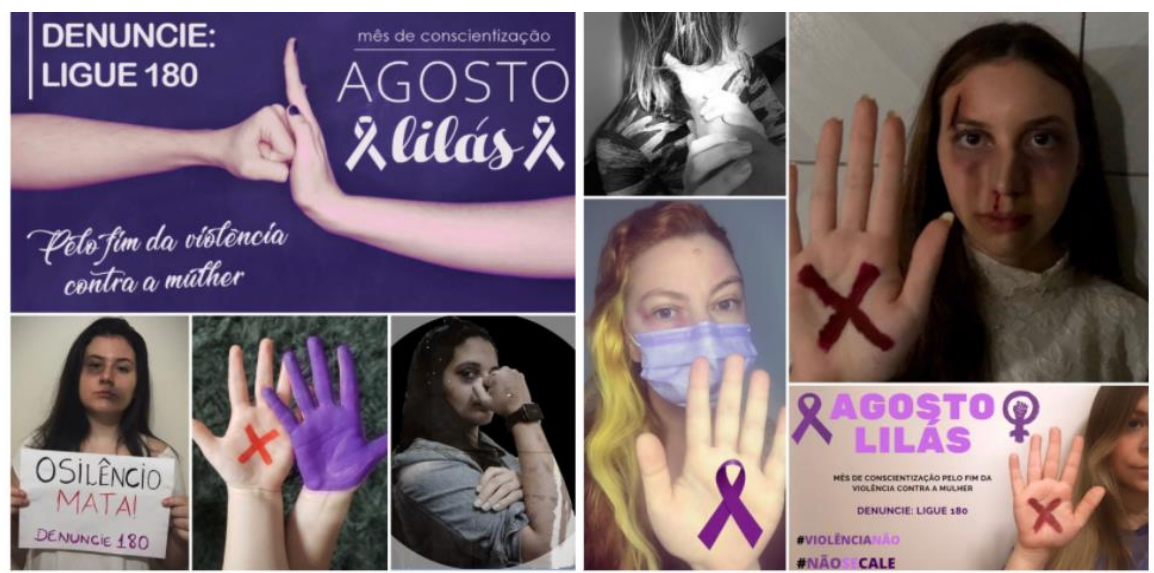

Figura 5. Campanha de conscientização pelo fim da violência contra a mulher, criada pelos alunos. Fonte: Montanari CC, 2021.

Além disso, a discussão de artigos científicos e diretrizes, traz o estímulo à leitura e discussão científica e a atividade já é parte das aulas presenciais e pode ser aplicado para o ensino remoto. Visa estimular os estudantes a realizar uma leitura crítica, para conhecer e analisar as evidências recentes sobre determinados assuntos. Tornando-se futuros profissionais mais críticos e reflexivos sobre a execução da sua prática profissional. Complementar a esta atividade é realizada a elaboração de resumos científicos. Durante a pandemia, os estudantes foram estimulados para criação de resumos científicos, visando a iniciação científica. A proposta foi aderida por um grande número de estudantes, que foram orientados pelos professores durante o desenvolvimento do trabalho. Os trabalhos foram 
enviados e apresentados de forma online na Semana de Enfermagem da Faculdade e do Hospital parceiro.

Demonstração e realização supervisionada (online) de técnicas e procedimentos de enfermagem: Mesmo diante da tela, os professores demonstraram habilidades profissionais do enfermeiro e após instigaram aos alunos que realizassem (quando possível) os procedimentos em suas casas. Foram desenvolvidas adaptações caseiras para as aulas práticas, como administração de medicação em garrotes e canudos, sinais vitais monitorados nos familiares, procedimento de higiene e conforto em bonecos, entre outros. Os alunos eram supervisionados pelos professores através dos vídeos. Por exemplo, na disciplina de Assistência de Enfermagem a Saúde do Adulto I, a professora capacitou os alunos para realização de uma entrevista, na sequência, ela convidou um familiar sua para participar da aula e estimulou os alunos que realizassem a entrevista da paciente simulada, incluindo identificação, queixa principal, história da doença pregressa e história da doença atual.

O nível de aprendizado foi verificado através de avaliações formativas e somativas, nas quais os alunos obtiveram desempenho satisfatório para a formação do enfermeiro, evidenciado na taxa de aprovação das disciplinas.

Durante o período das aulas remotas, foi realizada uma avaliação na qual os alunos puderam opinar como estava sendo a vivência do ensino. Ao serem questionados sobre a plataforma de transmissão das aulas ao vivo, $77 \%$ consideram a plataforma como "boa" ou "excelente". Na questão sobre as alternativas práticas propostas, necessárias diante da impossibilidade de uso dos laboratórios, 49\% apontaram como "regular" ou "bom" e 16\% como "excelente".

O maior resultado obtido diante neste momento foi que não houve evasão do curso. Ao contrário, verificou-se um aumento de $40 \%$ dos matriculados no primeiro semestre de 2021, em relação ao segundo semestre de 2020.

Ainda há grande preocupação quanto ao desenvolvimento de competências e habilidades práticas no ambiente virtual. No entanto, ainda não é possível avaliar o quanto a adaptação da vivência prática nessa etapa inicial da formação impactou na construção das habilidades destes alunos. Com o avanço na vacinação contra a COVID-19 e a redução no número de casos e óbitos, algumas aulas práticas essenciais foram retomadas no final do primeiro semestre de 2021, sempre respeitando as recomendações dos órgãos de saúde para prevenir a transmissão do coronavírus. Embora não tenhamos ainda como mensurar o impacto da pandemia sobre a formação dos estudantes, temos percebido através da manifestação deles uma grande insegurança na realização de procedimentos e uma ansiedade em querer recuperar o tempo perdido. 


\section{CONCLUSÃO}

O ensino remoto possibilita que os estudantes tenham acesso à educação de qualquer local e os recursos tecnológicos e as metodologias adaptadas ao ensino remoto têm sido grandes aliados no processo de ensino e aprendizagem da enfermagem no nível superior durante a pandemia. Os professores, buscando novas estratégias e metodologias, são capazes de transformar o ensino e diversificar e, assim, manter a atenção e a satisfação dos alunos.

O isolamento sanitário emergencial causado pela covid-19, expos que o uso da tecnologia no ensino será uma realidade daqui para frente. Observa-se que mesmo após quase dois anos de pandemia e uso do ensino remoto ainda somos desafiados no desenvolvimento de novas metodologias ativas de ensino e aprendizagem por parte dos docentes e para adequações a novas rotinas por parte de estudantes e familiares, não somente no uso de tecnologias disponíveis, mas também para desenvolver habilidades e práticas inerentes a profissão de enfermeiro (a). Além do desafio maior ainda, o de não aumentar a exclusão.

E por estes motivos o sistema de ensino deve estar preparado para se desenvolver e buscar alternativas para as dificuldades percebidas no ensino-aprendizado dos estudantes e na prática docente. Embora, em nosso estudo tenha sido possível evidenciar a satisfação dos alunos através da não evasão e a manutenção de níveis de aprendizagem nas avaliações, surgem outros desafios. Ainda não sabemos até quando irá perdurar a pandemia e com isso, manter os estudantes motivados e garantir que estejam aprendendo o conteúdo será uma tarefa cada vez mais difícil.

Além disso, apesar das diferentes metodologias adaptadas utilizadas no ensino da enfermagem não sabemos ainda ao certo como será o impacto na formação dos alunos a longo prazo.

\section{REFERÊNCIAS}

1. Noro LRA, Farias-Santos BCS, Sette-de-Souza PH, Pinheiro IAG, Borges REA, Nunes LMF, et al. O professor (ainda) no centro do processo ensino-aprendizagem em Odontologia. Rev ABENO [Internet]. 2015 Jun; 15(1):2-11.

Disponível:

https://revabeno.emnuvens.com.br/revabeno/article/view/146/130

2. OMS (Organização Mundial de saúde), 2020; Declaração do Diretor-Geral da OMS sobre o Comitê de Emergência do RSI sobre Novos Coronavírus (2019-nCoV). Disponível: $<$ https://www.paho.org/bra/index.php?option=com_content\&view=art icle\&id=6100:oms-declara-emergencia-de-saude-publica-deimportancia-internacional-em-relacao-a-novocoronavirus\&ltemid=812>. Acesso em: 31/08/2021. 
3. BRASIL. Ministério da Educação - MEC, PORTARIA № 343, DE 17 DE MARÇO DE 2020. Dispõe sobre a substituição das aulas presenciais por aulas em meios digitais enquanto durar a situação de pandemia do Novo Coronavírus - COVID-19. Disponível: https://www.in.gov.br/en/web/dou/-/portaria-n-343-de-17de-marco- -de-2020-248564376

4. Brasil, Ministério da Educação. PARECER HOMOLOGADO Despacho do Ministro, publicado no D.O.U. de 5/8/2021, Seção 1, Pág. 34. Acesso: 15/09/2021.

5. BRASIL. Conselho Nacional de Educação. Diretrizes para Educação a Distância na Educação Superior.

Disponível:portal.mec.gov.br/index.php?option=com_docman\&view= download\&alias=31361-parecer-cne-ces-564--15-

pdf\&category_slug=dezembro-2015-pdf\&ltemid=30192.

Acesso: 18 set. 2021.

6. Barbosa AM, Viegas MAS, Batista RLNFF. Aulas presenciais em tempos de pandemia: relatos de experiências de professores do nível superior sobre as aulas remotas. Revista Augustus, 2020. Rio de Janeiro, v.25, n.51, p.255-280.

7. Arndt KBF, Cruz, DM. O olhar do pedagogo para sua prática em tempos de pandemia. Educação, 2020. v.8; n.3, p. 644-660.

8. Moran J. Um conceito-chave para a educação, hoje. In: $\mathrm{BACICH}$, Lilian; TANZI NETO, Adolfo; TREVISANI, Fernando de Mello. Ensino híbrido: personalização e tecnologia na educação. Porto Alegre: Penso, 2015. p. 27-45.

9. Al-Yateem N, Dias JM, Subu MA, Abraham MS, Abd El-Baky F, Al Marzouqi A, Azizu Rahman S, Saifan AR, Mohammad MG, Alrimawi I, Faris M. Reflections on the transition to online teaching for health science education during the COVID-19 pandemic. Int J Med Educ. 2021 Aug v.26; n.12, p. 154-159.

10. Silva, Carla Marins et al. COVID-19 pandemic, emergency remote teaching and Nursing Now: challenges for nursing education. Revista Gaúcha de Enfermagem [online]. 2021, v. 42, n. spe. Disponível em: https://doi.org/10.1590/1983-1447.2021.20200248

11. BLOOM, B. S. et al. Taxonomy of educational objectives. New York: David Mckay, 1956. 262 p. (v. 1) 